\title{
O presente dos sistemas de governo na América Latina
}

Marvin Carvajal Pérez

\section{Resumo}

Em doutrina, costuma-se falar em um "modelo ibero americano de Governo". A herança colonial, bem como o desenvolvimento das novas repúblicas americanas no século XIX, determinou a instituição de governos fortes, caracterizados pela preeminência na figura do Presidente, tanto no âmbito político quanto no econômico e mesmo no administrativo. O típico governo da região tem uma relativamente fraca separação dos poderes, com um Executivo que participa -em alguns casos de forma excessiva- nos processos de criação normativa, bem como que se relaciona com o Judiciário em termos que podem atingir a independência de este. A volta da democracia na maioria dos países da região na década dos anos 80 tem atemperado esta superioridade do Presidente, fortalecendo os poderes de controle parlamentar, bem como a independência do Judiciário. No entanto, algumas das mais recentes emendas constitucionais latinoamericanas estão dirigidas a exacerbar o poder do Executivo, em detrimento da democracia.

Palavras-chave: Direito constitucional. Presidencialismo. Presidencialismo latino-americano.

\section{Introdução}

Os sistemas de governo constituem as formas segundo as quais, um Estado há organizado a estrutura política interna de poder. É o modelo de distribuição do poder entre os órgãos encarregados de realizar as funções básicas em uma sociedade organizada sob a forma estatal.

Diretor da "Escuela Judicial" da Costa Rica. Professor Associado da "Universidad de Costa Rica”. Doutor em Direito pela Universidade de São Paulo. Licenciado em Direito pela "Universidad de Costa Rica". 
Seguindo a clássica tipologia de Montesquieu bem como a mais recente de Loewenstein, a forma de governo está referida à posição que ocupam o Legislativo, o Executivo (a Administração) e o Judiciário na distribuição do poder político, bem como às diferentes relações existentes entre estas agências públicas. Quanto maior a separação dos poderes, maior a proximidade com o sistema presidencialista ou até com os regimes autoritários. Todavia, se maior a interação e colaboração entre estes, mais proximidade teremos do sistema parlamentarista. ${ }^{1}$

Cada sociedade, na hora de constituir seu pacto fundamental, deve decidir o tipo de governo que deseja. Daí que a Constituição seja o cenário natural em que se definirão os órgãos depositários do poder público, bem como a maneira em que estes se desenvolverão. Uma maior concentração de autoridade no Executivo deveria facilitar o efetivo exercício do poder (governabilidade), mas ao mesmo tempo dificultar o controle e diminuir a necessidade de produzir consensos para a tomada de decisões públicas de transcendência. Pelo contrário, a existência de mais controles e pontos de contato interinstitucional, favorece a consolidação de uma democracia inclusiva, ao tempo que impede o exercício "executivo" e expedito do poderEm termos de escolha entre o presidencialismo e o parlamentarismo, os diversos Estados têm optado por variações aos clássicos modelos: o inglês (paradoxo do sistema de sujeição parlamentar) e o estadunidense (modelo presidencialista por excelência). Desde a relativamente exitosa experiência européia com os modelos mistos (França, Portugal e a Finlândia como exemplo), até a evolução que apresentam os sistemas de governo latino-americanos, do presidencialismo caudilista à moderação parlamentar. Este breve ensaio dedicar-se-á a "sobrevoar" o cenário constitucional regional, com o intuito de determinar os traços do que se poderia chamar o modelo latino-americano de governo no começo do Século XXI.

\section{A herança colonial e o caudilismo}

$\mathrm{Na}$ América espanhola (motivo essencial deste trabalho), bem como na portuguesa, a sujeição colonial monárquica foi substituída com o Ascenso das novas elites militares e econômicas, que em alta medida reproduziram o modelo au-

\footnotetext{
${ }^{1}$ FERREIRA FILHO, Manoel Gonçalves. Curso de direito constitucional. São Paulo: Saraiva. 2002. p. 136.
} 
toritário trazido das metrópoles. Para a consolidação das novas formas de governo republicanas, os nascentes Estados tomaram como modelo a Constituição Federal dos Estados Unidos de 1787.

Esse fator produziu a difusão (não necessariamente o sucesso) do federalismo, ensaiado em quase todas as nações da região e consolidado formalmente em Brasil, Argentina, México e a Venezuela. Trouxe também a forma presidencialista de governo, segundo a qual o Presidente adquire largos poderes de condução da "res publica", ao tempo que mantém uma marcada separação com o Legislativo, carecendo de responsabilidade política recíproca entre ambos os poderes, pois obtém a legitimidade não da confiança parlamentar, mas do voto popular, mesmo que indireto.

O modelo resultou muito apropriado para as novas repúblicas ainda saudosas do poder não questionado dos "Virreyes”, dos “Capitanes Generales”, dos Capitães Hereditários e dos Governadores Gerais, já que simplesmente se substitui uma figura forte por outra. Esses espaços seriam no começo ocupados pelos caudilhos militares e posteriormente pelos líderes das nascentes oligarquias nacionais. ${ }^{2}$

O resultado desta "adaptação" do modelo norte-americano, bem como da demorada consolidação do ideário democrático e da persistência de estruturas produtivas altamente inequitativas, é o desenvolvimento de formas de governo que pouco evocam a evolução do presidencialismo estadunidense, constituindo sistemas próprios, compostos por elementos não identificáveis na matriz constitucional comum.

Fundamentalmente, o modelo presidencialista latino-americano caracteriza-se por estabelecer um Poder Executivo forte, onde a figura do Presidente é determinante na condução da vida política e econômica nacional. As suas atribuições chegam até a ultrapassar as clássicas fronteiras dos outros poderes, intervindo diretamente na atividade legislativa, e com maior o menor intensidade, também na judiciária.

Mesmo que muitos autores façam divisões entre tipos de presidencialismos na região, baseadas no grau de proximidade de cada um com o prin-

\footnotetext{
${ }^{2}$ SÁNCHEZ AGESTA, Luis. Curso de derecho constitucional comparado. Madrid: Editorial Universidad Complutense de Madrid. 1988. p. 244
} 
cípio democrático ou a mistura com elementos próprios do parlamentaris$\mathrm{mo}^{3}$, a verdade é que existem alguns traços comuns que -em maior ou menor grau- se observam em todos os ordenamento constitucionais da região. Não deveria resultar estranho que o modelo tenha servido como base institucional para a persistência de regimes autoritários durante boa parte dos séculos XIX e XX.

No entanto, as últimas décadas do século $\mathrm{XX}$ e os primeiros anos do XXI mostram um intenso processo de evolução do modelo para formas mais democráticas (e, paradoxalmente, para outras mais autoritárias) de governo. Mostra, ao mesmo tempo, um fortalecimento das instituições representativas e participativas e um movimento em procura de maior poder para o Executivo. As reformas em procura da reeleição presidencial ilimitada e a delegação plena de poderes legiferantes convivem ironicamente com a expansão da democracia na região. No próximo apartado, analizar-se-ão os traços essenciais do presidencialismo latino-americano no sentido clássico.

\section{Os caracteres do presidencialismo latino-americano}

Partir-se-á dos seguintes caracteres comuns ao sistema presidencialista latino-americano clássico: a eleição direta do Presidente; a concentração, neste funcionário, da Chefia do Estado, do Governo e da Administração; a figura do Chefe do Executivo como diretor da vida política pública, bem como da economia; a falta de responsabilidade recíproca em relação com o Legislativo; a subordinação dos ministros e outros órgãos públicos à Presidência; a intervenção do Executivo nas esferas de competência legislativa e judiciária.

\footnotetext{
${ }^{3}$ Colomer fala em presidencialismo hegemônico de exeção, presidencialismo hegemônico constitucional democrático, presidencialismo autônomo com separação dos poderes e presidencialismo de sujeção parlamentar. Cf. COLOMER VIADEL, Antonio. El presidencialismo iberoamericano y el Estado. In: CONGRESO IBEROAMERICANO DE DERECHO CONSTITUCIONAL, 4. MÉXICO: UNAM. 1992. p. 142. Por sua parte, Nogueira os divide em presidencialismo autoritário e democrático, pudendo ser este último puro ou atemperado. Cf. NOGUEIRA ALCALÁ, Humberto. Los regímenes presidenciales en América. In: CONGRESO IBEROAMERICANO DE DERECHO CONSTITUCIONAL. México: UNAM. 1992. p. 473.
} 


\section{a) Eleição direta}

$\mathrm{Na}$ América Latina, a regra é a eleição direta do Presidente. Assim o regulamentam as constituições da região: Argentina (artigo 94), Bolívia (96), Brasil (14), Chile (26), Colômbia (260), Costa Rica (93), Equador (165), El Salvador (80), Guatemala (184), Honduras (236), Nicarágua (146), Panamá (172), Paraguai (230), Peru (111), República Dominicana (88), Uruguai (151) e Venezuela (228). As experiências de voto indireto mediante colégios eleitorais é apenas histórica, destacando-se os casos da Argentina, Bolívia, Brasil e a República Dominicana.

O fato dos presidentes serem eleitos por meio do voto direto sem dúvida contribui a garantir o princípio democrático, ao aproximar mais o cidadão da decisão, mas ao mesmo tempo gera uma forte personalização da vida política latinoamericana. A pouca maturidade política dos corpos eleitorais faz com que a figura do candidato seja o centro do processo eleitoral, bem mais do que os próprios partidos políticos, as plataformas de governo e a ideologia do discurso.

Esta prevalência da pessoa sobre a estrutura partidária se reproduz posteriormente no Governo. O Presidente é o grande ator da vida política nacional. Os feitos do Governo são tidos como próprios do líder pela população. Daí que não seja estranho concluir que o Presidente adquire uma grande quantidade de poder político. Tal condição traduzir-se-á, no modelo latino-americano e como regra geral, na verticalidade das estruturas de governo, baseadas na hierarquia do chefe do Executivo a respeito dos ministérios ou secretarias de Estado, assim como da direção administrativa das autarquias e outras estruturas públicas.

\section{b) Chefia do Estado, do Governo e da Administração}

$\mathrm{Na}$ América Latina, é regra que os Presidentes são ao mesmo tempo, chefes do Estado, do Governo e da Administração Pública. Trata-se, de fato, de um dos caracteres principais dos sistemas presidencialistas, que não distribuem tais atribuições entre órgãos diversos, mas o concentram na figura do Presidente da República.

A Chefia do Estado está referida às competências que traduzem a unidade nacional em face da comunidade internacional (negociação e assinatura de tratados e outros instrumentos internacionais), a representação do Estado nas relações internacionais e diplomáticas (direção da política exterior, designação dos repre- 
sentantes diplomáticos do próprio país, bem como a recepção dos corpos diplomáticos estrangeiros), a defesa da integridade territorial (declaração da guerra e da paz, autorização para o ingresso de tropas estrangeiras), a direção das forças armadas (qualidade de Chefe do Exército, designação dos ministros militares bem como dos diretores dos corpos que compõem as forças armadas), a determinação da política monetária, etc.

No que tange a estes conteúdos, as leis fundamentais dos países da região outorgam ao Presidente as referidas tarefas como atribuições naturais: Argentina ( 99 incisos 7, 11, 12, 13, 14, 15 e 20), Bolívia (96 incisos 2, 3, 19, 20 e 21), Brasil (84 incisos VII, VIII, IX, X, XIII, XVIII, XIX, XX, XXI e XXII), Chile (32 incisos 9, 16, 17, 18, 19 e 20), Colômbia (189 incisos 2, 3, 4, 5, 6 e 7), Costa Rica (139 incisos 2 e 3, 140 incisos 1, 4, 6, 8, 9, 11, 12 e 15), Cuba (93 incisos a, g, h, i e j), Equador (171 incisos 12, 13, 14, 15, El Salvador (168 incisos 2, 3, 4, 5, 11, 12, 13, 17, 18 e 19), Guatemala (183 incisos 2, 3, 4, 1, 16 e 17), Honduras (245 incisos 2, 3, 4, 12, 3, 14, 15, 16, 17, 36 e 37), México (89 incisos IV, V, VI, VII, VIII, IX e X), Nicarágua (95, 144 e 150 incisos 2 e 8), Paraguai (238 incisos 1, 7 e 9), Peru (118 incisos 2, 10, 11, 12, 13, 14 e 15), República Dominicana (55 incisos 4, 5, $12,13,14,15$ e 16), Uruguai (159 e 168 incisos $1,2,10,11,12,15,16,17$ e 20,) e Venezuela (236 incisos 4, 5 e 6 ).

Por sua vez, a Chefia de governo diz respeito às competências relacionadas com a condução dos processos políticos internos, a relação do Executivo com os outros poderes. Trata-se, mormente, de atribuições discricionárias que o Presidente adota protegido pela independência funcional que o separa do arbítrio dos outros poderes constitucionais. As chamadas funções políticas ou governativas do Presidente latino-americano são em geral: a possibilidade de participar no procedimento legislativo ${ }^{4}$, de preparar e submeter ao Congresso os projetos de Orçamento do Estado, de intervir na designação de determinados funcionários dos outros poderes ${ }^{5}$, de conceder o indulto, de emitir regulamentos às leis formais, decretar o Estado de emergência, etc.

\footnotetext{
${ }^{4}$ Esta competência será objeto de desenvolvimento em um tema separado, dada a sua importância na caracterização do Executivo no contexto latino-americano.

${ }^{5} \mathrm{O}$ tema relacionado com a intervenção do Executivo na designação dos membros do Poder Judiciário será analisado mais adiante, quando se discutir a relação entre ambos os poderes no Presidencialismo latino-americano.
} 
As constituições da região estabelecem a Chefia de Governo dos presidentes em forma ampla: Argentina (99 incisos 2, 3, 4, 5, 8, 9, 19 e 20), Bolívia (96 incisos 1, 4, 5, 6, 7, 13, 16 e 17), Brasil (84 incisos I, III, IV, V, X, XI, XII, XV, XVI, XXIII, XXIV, XXV, XXVI), Chile (32 incisos 1, 2, 3, 4, 6, 8, 12, 13 e 15), Colômbia (189 incisos 1, 8, 9, 10 e 11), Costa Rica (139 inciso 1, 140 incisos 2, 3, 4, 5, 11, 14 e 15), Cuba (93 incisos a, b, c, ch, d, e, ll), Equador (171 incisos 2, 3, 4, 5, 6, 7, 8, 10, 19 e 20), El Salvador (168 incisos 6, 7, 8, 10 e 16), Guatemala (183 incisos 5, 7, 8, 10, 12 e 13), Honduras (245 incisos 1, 5, 6, 9, 11, 20, 24,25, 30 e 33), México (69, 89 incisos I, II, II, XI, XIII, XIV, XV, XVI e XVIII), Nicarágua (150 incisos 3, 4, 5, 6, 7, 10, 13 e 15), Paraguai (238 incisos 3, 4, 5, 6, 10, 11, 12 e 14), Peru (118 incisos 3, 5, 6, 7, 20 e 21), República Dominicana (55 incisos 1, 2, 7, 8, 9 e 25), Uruguai (168 incisos 4, 5, 6,7 e 8 ) e Venezuela (236 incisos $2,3,8,9,10,14,16,17,18,19$ e 21 ).

Finalmente, a Chefia da Administração Pública não é uma das categorias clássicas do Direito Político para diferenciar as funções clássicas do Executivo em regimes parlamentaristas e presidencialistas. Trata-se do fato de colocar o Presidente como a cabeça da Administração Pública, como chefe (relação de hierarquia) de toda a Administração Central e diretor (relação de direção funcional) da Autárquica. Este fato sem dúvida verticaliza a estrutura de prestação dos serviços públicos, em detrimento do caráter técnico da função administrativa, o qual recua em favor das valorações e motivações políticas do Presidente, com prejuízo potencial ao interesse geral.

As constituições latino-americanas estabelecem diversas modalidades de chefia administrativa como parte das competências dos presidentes: designar diversos funcionários da Administração, mesmo alguns cargos técnicos (Bolívia 96 inciso 15, Colômbia 189 inciso 13, Costa Rica 140 inciso 2, México 89 inciso II, Nicarágua 150 inciso 6, Panamá 179 inciso 6, Paraguai 238 inciso 6, República Dominicana 55 inciso 1, Uruguai 168 inciso 9 e Venezuela 236 inciso 16); exercer a direção superior da Administração, emitindo políticas gerais de atuação, bem como ordens concretas para diversos órgãos e entes administrativos (Brasil 84.II, Chile 24, Equador 164 e 171 inciso 9, Honduras 245 incisos 28, 29 e 30, Peru 118 inciso 23, e a República Dominicana 55 caput); distribuir as cargas de trabalho entre os diversos órgãos da Administração, de acordo com seu critério discricionário (Colômbia 189 inciso 17); controlar a correta prestação dos serviços públicos, bem 
como da sua adaptação aos planos de desenvolvimento (Colômbia 189 incisos 21 e 22, Costa Rica 140 inciso 7, Cuba 93 inciso c, El Salvador 168 inciso 5, Honduras 245 inciso 35 e Panamá 179 inciso 10); revogar os atos das diversas administrações, até em alguns casos de autoridades provinciais e municipais (Cuba 90 incisos ñ e o, e a República Dominicana 55 inciso 23); assumir a direção de órgãos da Administração (Cuba 93 inciso ch); administrar a Receita Pública para garantir que as contas do Estado coincidam com a Lei do Orçamento (Argentina 99 inciso 10, Honduras 245 inciso 19, Panamá 179 inciso 5, Paraguai 238 inciso 13, Peru 118 inciso 16, Uruguai 168 inciso 18 e Venezuela 236 inciso 11); autorizar a alienação de bens públicos dos Municípios, competência que na maioria dos paises da região é reservada ao Poder Legislativo (República Dominicana 55 inciso 24).

A concentração, em uma única pessoa, de competências tão diversas e abrangentes, faz com que os poderes de controle por parte do Legislativo percam muita da sua real efetividade. Os poderes de direção do Executivo lhe conferem uma autoridade discricionária muito acentuada, ao ponto que -se combinados com uma maioria governante cômoda- as diretivas do Executivo serão pacificamente aprovadas.

Algumas destas atribuições, no entanto, significam um perigo imediato na democracia e na eficaz prestação dos serviços públicos. Um exemplo é a grande liberdade do Executivo para designar e destituir funcionários públicos, que pode propiciar o clientelismo e o nepotismo na composição dos quadros diretivos no setor público. ${ }^{6}$ Estes fatores favorecem o tráfico de influencias, constituindo verdadeiros círculos viciosos que afetam não apenas a moralidade da função administrativa, mas também a sua efetividade na satisfação dos interesse geral.

\section{c) Inexistência de responsabilidade recíproca entre o Executivo e o Legislativo}

Ao contrário do que acontece nos modelos parlamentares, é uma característica comum aos sistemas presidencialistas que entre o Executivo e o Legislativo não exista uma relação de confiança recíproca. Os membros do Executivo não o são

\footnotetext{
${ }^{6}$ Para alguns autores, de fato, o clientelismo e o nepotismo são em si próprios caracteres do Presidencialismo latino-americano. Cf. COLOMER VIADEL, Antonio. El presidencialismo iberoamericano y el Estado. In: CONGRESO IBEROAMERICANO DE DERECHO CONSTITUCIONAL, 4. México: UNAM, 1992. p. 137.
} 
também do Parlamento; existem geralmente regras que disciplinam a incompatibilidade dos cargos de deputado ou senador e ministro, dispondo como exceção o caso dos parlamentares serem afastados provisoriamente durante enquanto ocuparem a pasta ministerial; os ministros não são designados pelo Poder Legislativo nem podem ser destituídos por este pela simples perda de confiança parlamentar, salvo previsão constitucional expressa, presente em apenas algumas constituições da região; contudo, o Presidente não pode dissolver o Legislativo nem intervir diretamente em suas decisões orgânicas (interna corporis). Estes caracteres estão presentes de modo geral nas constituições latino-americanas.

A já mencionada prevalência da figura do Presidente no cenário político regional tem origem parcial nessa maior separação a respeito do Legislativo, o que se traduz em uma maior independência funcional e política em favor do Chefe do Executivo, bem como a correlativa diminuição no perfil do Parlamento. A liderança que o Presidente geralmente exerce em relação com o Parlamento nos regimes presidencialistas é devida mais aos esforços por manter uma sólida base governista mediante acordos e pactos com as bancadas próximas ao Partido no poder do que em uma relação formal de dependência recíproca entre ambos os poderes do Estado.

As leis fundamentais dos países da região refletem esse esquema de divisão funcional entre o Legislativo e o Executivo, ao determinar a eleição direta do Presidente $^{7}$, a designação dos Ministros ou Secretários por parte do Presidente (Bolívia 99, Brasil 84 inciso I, Chile 32 inciso 9, Colômbia 189 inciso 1, Costa Rica 139 inciso 1, Equador 171 inciso 10 e 176, El Salvador 162, Guatemala 183 inciso 20, Honduras 245 inciso 5, México 89 inciso 3, Nicarágua 150 inciso 6, Panamá 178 inciso 1, Paraguai 238 inciso 6, República Dominicana 55 inciso 1, Uruguai 174 e Venezuela 236 inciso 4); a incompatibilidade do exercício simultâneo dos cargos de Deputado e Ministro (Bolívia 49 e 50, Chile 54, Colômbia 180 inciso 1, Costa Rica 109, Equador 139, El Salvador 127 inciso 1 e 129, Guatemala 160, Honduras 199 inciso 3, México 55 inciso 5, Nicarágua 134 inciso 2, Panamá 150, Paraguai 196, República Dominicana 18, Uruguai 122 e Venezuela 189 inciso 1); a consideração dos ministros como colaboradores imediatos do Presidente (Chile 33, Honduras 247, e Venezuela 242); a distribuição discricionária de funções entre os Ministros

\footnotetext{
7 Tema já tratado em apartado anterior.
} 
por parte do Presidente (Colômbia 180 inciso 17, Equador 176, Panamá 190, Peru 127 e Uruguai 174).

\section{d) Funções legislativas}

Um dos traços característicos nos sistemas presidencialistas é a determinante participação do Poder Executivo na formação da lei. É normal, nos modelos que privilegiem maiores graus de separação dos poderes, que o Executivo tenha intervenção na iniciativa parlamentar, bem como na promulgação final da lei. Ora, as constituições latino-americanas recolhem esta tradição, dispondo, além a iniciativa dos processos legislativos, a possibilidade do Governo decidir a respeito dos temas que o Parlamento decidirá em determinados períodos do mandato parlamentar, a sanção dos projetos, bem como o veto por motivos de inconveniência ou inconstitucionalidade, a promulgação e a publicação da lei. O Governo tem ainda poderes suficientes para regulamentar a lei formal, dispondo a respeito dos detalhes não contemplados expressamente pelo legislador, permitindo a efetiva implementação do texto.

A conjunção destes fatores produz uma realidade inquestionável, como é que a função legiferante cabe tanto ao Legislativo, que a tem como competência precípua, quanto ao Executivo. A intervenção deste último é decisiva na consolidação do processo legislativo. A coexistência das referidas atribuições com outros caracteres do presidencialismo latino-americano gera condições que deveriam facilitar o exercício ágil do governo. Nos casos em que este tem uma maioria parlamentar suficiente, a possibilidade de decidir o rumo das futuras mutações legislativas é substancial. Destarte, a execução da lei o será, em boa medida a das próprias diretivas dimanadas do Governo.

Contudo, as constituições latino-americanas determinam diversas competências executivas no plano normativo que vão além da tradicional participação do Executivo na função legiferante. É assim como ao Presidente é reconhecida a possibilidade de emitir atos com força de lei, mormente em situações de emergência, mas cujo emprego por parte dos governos da região tem extravasado este limite circunstancial, bem como os de tipo material dispostos com a finalidade de evitar excessos no exercício deste poder.

Os ordenamentos normativos regionais, em diferentes graus, ainda permitem que o Legislativo autorize a delegação ou autorização provisória da função 
criadora da lei formal ao Executivo, especialmente ao Presidente. Trata-se de uma exceção ao princípio de reserva da lei em determinadas matérias. O exercício desta função pode facilitar a implementação das políticas públicas, ao permitir uma resposta normativa mais ágil e executiva, mas se usada de maneira excessiva ou abusiva, também poder-se-ia constituir em uma forma de superar o próprio princípio da separação dos poderes, base do sistema republicano. Dependerá muito da maturidade de cada sistema político, bem como da solidez das instituições democráticas em cada Estado, o que determinará o emprego regular ou ilegítimo da mencionada competência. ${ }^{8}$

A respeito da função legislativa, as constituições latino-americanas regulamentam os seguintes aspectos: a iniciativa na formação da lei por parte do Poder Executivo (Argentina 77, Bolívia 71, Brasil 67 e 84 inciso III, Chile 62, Colômbia 200 inciso 1, Costa Rica 123, Cuba 90 inciso d, Equador 171 inciso 4, El Salvador 132 inciso 2, Guatemala 183 inciso 7, Honduras 213, México 71 inciso 1, Nicarágua 150 inciso 3, Paraguai 238 inciso 12, Peru 107, República Dominicana 38 inciso b, Uruguai 168 inciso 7 e Venezuela 298); os poderes de sanção, publicação e veto dos projetos de lei ${ }^{9}$ (Argentina 99 inciso 3, Bolívia 76, Brasil 68 inciso I, Chile 32 inciso 1, Colômbia 189 inciso 9 e 10, Costa Rica 140 inciso 3, Equador 171 inciso 4, El Salvador 135, Guatemala 183 inciso 8, Honduras 215 y 216, México 89 inciso 1, Nicarágua 150 inciso 3, Paraguai 179 inciso 1, Peru 108, República Dominicana 55 inciso 3, Uruguai 168 inciso 6 e Venezuela 214); poder regulamentar (Argentina 99 inciso 2, Chile 32 inciso 8, Colômbia 289 inciso 11, Costa Rica 140 inciso 3, Equador 171 inciso 5, El Salvador 132 inciso 14, Guatemala 183 inciso 5, Honduras 245 inciso 11, México 89 inciso I, Nicarágua 150 inciso 4 e 10, Panamá 179 incisos 10 e 14, Paraguai 169 inciso 6, Peru 118 inciso 8, República Dominicana 155 inciso 2, Uruguai 158 inciso 4 e Venezuela 236 INCISO 10); e poder legislativo delegado

${ }^{8}$ O Professor Manoel Gonçalves Ferreira Filho considera que a intervenção do Executivo na criação da lei formal, mesmo em casos em que atua de maneira direta, não contradiz o modelo da separação dos poderes, sempre que os sistemas políticos estabeleçam regras claras e controles efetivos a respeito dos limites de tal competência normativa. FERREIRA FILHO, Manoel Gonçalves. Do processo legislativo. São Paulo: Saraiva. 2002. p. 159-169.

${ }^{9}$ No caso de Brasil, Colômbia, Equador e Peru é ainda estabelecida a possibilidade do veto parcial, em tanto não altere o sentido do projeto submetido a conhecimento do Poder Executivo. 
(Argentina 76, Bolívia 71, Brasil 84 inciso XVI ${ }^{10}$, Chile 32 inciso 3, Cuba 90 inciso c, ch e $\mathrm{m}^{11}$, Paraguai 101 inciso 4, e Venezuela 236 inciso 8).

\section{e) Relação com o Poder Judiciário}

Finalmente, o presidencialismo latino-americano caracteriza-se por estabelecer relações entre o Poder Executivo e o Judiciário que vão além da clássica colaboração na execução das sentenças e outras decisões jurisdicionais. Em termos gerais, os poderes executivos da região têm ingerência na nomeação dos ministros das supremas cortes. ${ }^{12}$ Em alguns casos, podem designar substitutos em casos de ausência dos titulares durante vigência de recesso parlamentar. ${ }^{13}$ Em casos extremos, podem até emitir diretrizes dirigidas aos órgãos judiciais. ${ }^{14}$

O fator adicionado por este relacionamento entre o Executivo e o Judiciário nos regimes presidencialistas latino-americanos potencia o poder dos presidentes, mas ao mesmo tempo acrescenta as possibilidades de atingir a independência do Judiciário. O resultado final é a conformação dos órgãos superiores do Judiciário segundo as linhas ideológicas do governo de turno, o que no caso dos regimes competitivos, onde há alternância no poder, favorece a governabilidade e reconhece que os tribunais da mais alto nível requerem de determinada sensibilidade política e não apenas de conhecimento técnico.

\section{Caracteres especiais do presidencialismo latino-americano}

Mesmo sendo a regra a grande concentração de poder por parte do Executivo, em especial do Presidente no cenário constitucional latino-americano, em

\footnotetext{
${ }^{10}$ Sob a forma das medidas provisórias.

${ }^{11}$ Neste caso inclui o poder de interpretar autenticamente as leis e a aprovação dos tratados internacionais.

${ }^{12}$ Tal o caso das constituições da Argentina (90 inciso 4), que prevê a nomeação, não apenas dos ministros do mais alto tribunal, mas também a dos demais juízes federais; em ambos os casos, a designação é feita pelo Senado. O Brasil o estabelece no artigo 84 inciso XVI, o Chile no 32 inciso 13, o México no artigo 96 e na Nicarágua no 150 inciso 15.

${ }^{13}$ Cf. A Constituição da Argentina no artigo 90 inciso 19 permite a designação provisória sem o concurso do Senado em casos de recesso da Casa. Regra similar é prevista nas constituições da Bolívia (96 inciso 16), e na República Dominicana no artigo 55 inciso 9.

${ }^{14}$ É o caso da constituição cubana, que no artigo 90 inciso h dispõe a possibilidade do Executivo (Conselho de Estado) de dirigir instruções gerais para os tribunais.
} 
prejuízo do controle parlamentar, a verdade é que existem exceções que inserem alguns caracteres próprios dos regimes parlamentares, atemperando em alguma medida a prevalência do Presidente.

Tal é o caso da responsabilidade que, na Argentina, tem o Chefe do Gabinete em relação com o Legislativo (artigo 100). Este órgão do Executivo tem ainda funções que lhe conferem um caráter semi-parlamentar. É o que se relaciona diretamente com o Congresso da Nação, alem de ser o órgão máximo da Administração.

No caso de Cuba, mesmo com as particularidades de um regime não competitivo de partido único e o que isto representa no sistema de governo, deve ser mencionada a regra segundo a qual, a designação dos ministros é realizada pela Assembléia Nacional do Poder Popular (órgão legislativo), segundo dispõe o artigo 93 inciso ch) da sua Constituição.

Tem também o efeito vinculante que a algumas constituições estabelecem ao voto de censura que o Parlamento profira em contra de um ministro do Governo. É assim regulamentado em El Salvador (168 inciso 6), no Uruguai (artigo 148) e na Venezuela (artigo 246). A censura vinculante é um instituto próprio do parlamentarismo, "importada" para os sistemas presidencialistas em casos de faltas graves aos deveres de rendição de contas junto ao Congresso.

Finalmente, é prevista em quase todas as constituições a interpelação dos ministros de governo por parte do Legislativo. Diante do chamado por parte do Parlamento, é dever dos funcionários comparecerem para responder as questões que lhes forem levantadas. Exemplos de este tipo de regulação temos na Colômbia (artigo 135 inciso 9), na Costa Rica (artigo 121 inciso 24), no Equador (artigo 179 inciso 5), na Guatemala (artigos 166 e 167), no Paraguai (artigo 193) e no (artigo Uruguai 119). Excetuados os casos já mencionados, as constituições não estabelecem quaisquer conseqüências jurídicas se os funcionários se recusarem de comparecer. No entanto, este instituto potencia o papel do Legislativo como órgão de controle. Em caso de não ter o Presidente uma base governista suficiente, a efetividade da interpelação se multiplica como mecanismo de oposição.

Também deve ser mencionado um preocupante processo de concentração do poder por parte do Executivo em alguns sistemas constitucionais latino-ame- 
ricanos. É o caso da Venezuela, onde está sendo cogitada a reeleição indefinida do Presidente e recentemente, foi implementada uma larga delegação de poderes legislativos. ${ }^{15}$ Se encontram neste momento em andamento processos de reforma constitucional na Bolívia e no Equador, cujos resultados devemos esperar para determinar se o caso venezuelano é uma exceção ou a nova regra na região.

\section{Conclusão}

Os sistemas de governo da América Latina têm se caracterizado por adotar e aprofundar os clássicos elementos do presidencialismo norte-americano. Mesmo existindo variações de país em país, as linhas gerais confluem em alguns temas centrais, que basicamente conferem grandes poderes ao Poder Executivo, em prejuízo do controle do Legislativo.

A figura do Presidente da República é a que maior destaque tem nos sistemas latino-americanos. Trata-se não apenas do Chefe do Estado e do Governo. Também é a cabeça da Administração Pública, detém largos poderes normativos a até poder ingerir na conformação do Poder Judiciário.

No entanto, o contexto constitucional latino-americano não é uma realidade plana. Apresenta particularidades que situam alguns regimes mais perto do semipresidencialismo. Há também movimentos (alguns reais, outros apenas noticiados) de aprofundamento do poder do Presidente, em detrimento do princípio democrático.

Não há um sistema de governo ideal e, mesmo considerando as vantagens que os modelos parlamentares e semi-parlamentares apresentam na Europa, a historia latino-americana parece ter propiciado a instituição do presidencialismo. O desafio é construir uma forma que permita a governabilidade, mas que para atingir tal objetivo não sacrifique a liberdade, o império do sistema democrático e a satisfação do interesse geral.

15 Tema que, no entanto, não é novo na realidade regional. Mesmo depois da volta a democracia que muitas nações da região experimentaram desde a década dos anos oitenta, alguns casos temporais de retrocesso para sistemas mais autoritários aconteceu na Argentina de Menem e o Peru de Fujimori. Em ambos os casos, as decisões governamentais puderam ser implementadas com maior facilidade graças ao estabelecimento de amplos poderes de delegação da função legislativa em favor do Executivo. 


\title{
The actual government system in Latin America
}

\begin{abstract}
The Legal Academics called it the "Latin American Way of Government". The colonial heritage, as well as the development of the "New Republics" in the XIX Century, allowed the creation of strong governments, with a preeminent presidency in policy making powers, in the economy and administrative matters. The typical region's government has a relatively weak separation of powers, with an Executive Branch that widely participates in Law Making initiatives, sometimes more than reasonable, as well as a very close relation with the Judiciary Branch, enough to be able to put its independence at risk. The return to the Democracy experimented by many Latin American countries in the 80's has decreased the superiority of Presidents, producing more and stronger ways of Legislative and Judiciary control. However, some of the most recent Latin American constitutional amendments are intended to enhance the power of Executive Branch, in direct conflict with the democratic ideals.
\end{abstract}

Keywords: Constitutional Law. Presidencialism. Latin-american presidencialism.

\section{Referências}

BOBBIO, Norberto. A teoria das formas de governo. Brasília: UnB, 1994.

BOLÍVIA. Asamblea Constituyente. Disponível em: <http://www. constituyente.bo/ index.php>.

BOSCH, Juan. Las dictaduras dominicanas. Santo Domingo: Alfa y Omega, 1998.

CAGGIANO, Monica Herman Salem. Oposição na política. São Paulo: Angelotti, 1995.

CANOTILHO, José Joaquim Gomes. Direito constitucional e teoria da constituição. Coimbra: Almedina, 2003.

COLOMER VIADEL, Antonio. El presidencialismo iberoamericano y el Estado. In: CONGRESO IBEROAMERICANO DE DERECHO CONSTITUCIONAL, 4. México: UNAM, 1992. 
CONSTITUCIONES de Iberoamérica. Instituto de Derecho Público Comparado. Universisdad Carlos III e Madrid. Disponível em: <http://www.uc3m.es/uc3m/ inst/MGP/consibam.htm>. Acesso em: 30 set. 2008.

CONSTITUCIONES hispanoamericanas. Biblioteca Virtual Miguel de Cervantes. Disponível em: <http://www.cervantesvirtual.com/portal/ constituciones/enlaces. shtml>. Acesso em: 30 set. 2008.

FERREIRA FILHO, Manoel Gonçalves. Curso de direito constitucional. São Paulo: Saraiva, 2002.

. Do processo legislativo. São Paulo: Saraiva, 2002.

HARO, Ricardo. Reflexiones en torno del presidencialismo argentino. In: CONGRESO IBEROAMERICANO DE DERECHO CONSTITUCIONAL. México: UNAM, 1992.

HERNÁNDEZ VALLE, Rubén. El derecho de la constitución. San José: Juricentro, 1993.

NOGUEIRA ALCALÁ, Humberto. Los regímenes presidenciales en América. In: CONGRESO IBEROAMERICANO DE DERECHO CONSTITUCIONAL. México: UNAM, 1992.

POLITICAL database of the Americas. Georgetown University, 2006. Disponível em: <http://pdba.georgetown.edu>. Acesso em: 30 set. 2008.

PRATS, Eduardo Jorge. Derecho constitucional. Santo Domingo: Gaceta Judicial, 2005.

REQUEJO, Paloma. Democracia parlamentaria y principio minoritario. Barcelona: Ariel, 2000.

RODRÍGUEZ R. Libardo. Estructura del poder público en Colômbia. Santafé de Bogotá: Temis, 1999.

SÁNCHEZ AGESTA, Luis. Curso de derecho constitucional comparado. Madrid: Editorial Universidad Complutense de Madrid, 1988.

STONE, Geoffry R. et al. Constitutional law. New York: Aspen Law and Business, 2001. 